\title{
Lithium Organochalcogenides Promoting Michael-aldol Tandem Reactions
}

\author{
Bruno A. de Sousa*, Fábio G. Zanin and Alcindo A. Dos Santos \\ Instituto de Química - Universidade de São Paulo, São Paulo, Brazil \\ *bruno.sousa@usp.br
}

Keywords: Tandem reactions, chalcogenides, organometallics.

\section{INTRODUCTION}

Tandem reactions show itself as a very attractive methodology in the scope of total synthesis, allowing important transformations in the construction of multifunctionalized carbon skeletons ${ }^{1}$. Furthermore, was proven that lithium organochalcogenides are good nucleophiles in Michael-aldol-tandem reactions and the resulting adducts are considered immediate precursors of Baylis-Hillman adducts ${ }^{2}$.

\section{RESULTS AND DISCUSSION}

The study was conducted with different classes of Michael acceptors as well as aldehydes as the aldol electrophile. As can be seen in Scheme 1 a large number of products were prepared by the one-pot procedure.

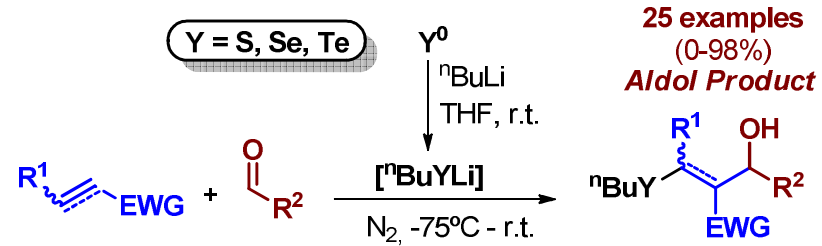

EWG $=\mathrm{SO}_{2} \mathrm{Ph}, \mathrm{SOPh},(i-\mathrm{Pr})_{2} \mathrm{NCO}, \mathrm{CO}_{2} \mathrm{Et}, \mathrm{CN}$, $\mathbf{R}^{1}=\mathrm{H}, \mathrm{Me}$ $\mathrm{R}^{2}=$ alkyl, aryl<smiles>CC(C)CC(C)C(C)C(O)c1ccccc1</smiles>

$175 \%$<smiles>CCCCC(C)C(C(=O)OCC)C(O)c1ccccc1</smiles>
$285 \%$<smiles>CCOC(=O)C(=C(C)CC)C(O)c1ccccc1</smiles>

$392 \%$<smiles>CCCCCC(O)C(C(=O)N(C(C)C)C(C)C)c1ccccc1</smiles>

a $\mathrm{Y}=\mathrm{Te}, 42 \%$
b $\mathrm{Y}=\mathrm{Se}, 85 \%$<smiles>CC(C)(C)CCC(O)C(O)c1ccccc1</smiles>
$\mathrm{Ph}$<smiles>CC(C)(C)CC(C(=O)Pc1ccccc1)C(O)c1ccccc1</smiles>

a $\mathrm{Y}=\mathrm{Te}, 0 \%$ b $Y=S e, 93 \%$ c $\mathrm{Y}=\mathrm{S}, \mathbf{5 7 \%}$

Scheme 1. Standard reaction conditions for the three component protocol and some exemples of the obtained adducts.
We also investigated the possibility to perform a one-pot trapping of the intermediate alcoxide anion from the aldol reaction with carboxylic acid chlorides. The sequential procedure allows performing in a single flask the Michael-aldol, acylation and chalcogen elimination reactions resulting in the corresponding acylated BayllisHillman adducts in very good yields. In addition, these compounds can be converted in highly substituted six-membered ring lactones as shown in Scheme 2.

$$
\begin{aligned}
& {\stackrel{0}{R^{1}}}
\end{aligned}
$$

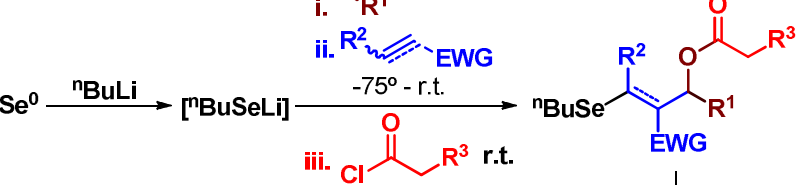

$$
\begin{aligned}
& \mathrm{R}^{3}=\text { alkyl, aryl } \\
& \mathrm{H}_{2} \mathrm{O}_{2}(60 \%) \\
& \text { one-pot } \\
& \underbrace{O}_{\text {EWG }} \\
& \text { generic structure } \\
& \text { Base } \\
& \underbrace{R_{(85-93 \%)}^{13}}_{\text {EWG }}
\end{aligned}
$$

Scheme 2. Standard reaction conditions for the four component protocol.

\section{CONCLUSION}

In conclusion, a general procedure for three and four component Tandem reactions has been developed, leading to the expected products in good yields. The one pot procedure allows the preparation of complex substrates in a single reaction flask using elemental chalcogenide as starting material.

\section{ACKNOWLEDGEMENTS}

The authors thank FAPESP, CAPES and CNPq for the financial support.

\section{REFERENCES}

${ }^{1}$ Parsons, P. J.; Penkett, C. S.; Shell, A. J. Chem. Rev. 1996, 96, 195-206.

${ }^{2}$ Keppler, A. F.; Gariani, R. A.; Lopes, D. G.; Comasseto, J. V. Tetrahedron Lett. 2009, 50, 2181. 